\title{
Pemberdayaan Masyarakat Melalui Unit Usaha Simpan Pinjam Di Badan Usaha Milik Kampung Kampung Minas Barat
}

\author{
Koko Saputra \\ Program Studi Pascasarjana Ilmu Administrasi Publik Universitas Riau \\ Korespondensi : kokosaputra015@gmail.com
}

\begin{abstract}
Abstrak
BUMDes merupakan wadah swadaya yang pada hakekatnya merupakan wadah yang melakukan pemberdayaan kepada masyarakat, namun keadaan saat ini banyak yang tidak mampu berfungsi sebagai wadah pemberdayaan masyarakat BUMDes. Penelitian ini bertujuan untuk mengetahui pemberdayaan masyarakat melalui Unit Usaha Simpan Pinjam pada Badan Usaha Milik Desa Mineh Mandiri Desa Minas Barat dan Untuk Mengetahui faktor-faktor apa saja yang menghambat pemberdayaan masyarakat melalui Unit Usaha Simpan Pinjam pada Badan Usaha Milik Desa Mineh Mandiri Desa Minas Barat. Penelitian ini menggunakan pendekatan metode penelitian deskriptif kualitatif. Data primer diperoleh secara langsung melalui wawancara dengan informan yaitu Direktur BUMDes Mineh Mandiri, Kepala Desa Minas Barat, perwakilan masyarakat Desa Minas Barat, Ahli Lapangan BUMDes, dan Masyarakat Peminjam. Hasil penelitian ini menunjukkan bahwa pemberdayaan masyarakat melalui unit usaha simpan pinjam pada Badan Usaha Milik Desa Mineh Mandiri Desa Minas Barat adalah Buruk. faktor penghambat dalam pemberdayaan masyarakat melalui unit usaha simpan pinjam di BUMDes Mineh Mandiri Desa Minas Barat adalah keterbatasan SDM dan kurangnya kesadaran masyarakat serta kurangnya antusias masyarakat terhadap BUMDes Mineh Mandiri.
\end{abstract}

Kata kunci: Pemberdayaan masyarakat, Simpan Pinjam

\begin{abstract}
Village Owned Enterprise is a self-help container that is essentially a forum that conducts empowerment to the community, but the current situation is many unable to function as a forum for community empowerment of Village Owned Enterprise. This research aims to determine community empowerment through The Save Borrow Business Unit in Village Owned Enterprise Mineh Mandiri West Minas Village and to Know what factors hinder community empowerment through the Simpan Pinjam Business Unit in Village Owned Enterprise Mineh Mandiri West Minas Village. This research uses qualitative descriptive research method approach. Primary data obtained directly through interviews from informants, namely the Director of Village Owned Enterprise Mineh Mandiri, Village Chief Of West Minas, representative community Of West Minas Village, Field Experts Of Village Owned Enterprise, and Borrower Community. The results of this study show that community empowerment through the business unit of saving loans in a Village Owned Enterprise Mineh Mandiri West Minas Village is Bad. inhibitory factors in community empowerment through business units save borrowing in Village Owned Enterprise Mineh Mandiri West Minas Village is the limitation of human resources and lack of public awareness and lack of public enthusiasm for Village Owned Enterprise Mineh Mandiri.
\end{abstract}

Keywords: Community empowerment, Save and Borrow 


\section{PENDAHULUAN}

Pembangunan ekonomi merupakan suatu langkah yang harus diambil oleh pemerintah. Pembangunan ekonomi adalah suatu langkah yang diambil pemerintah untuk meningkatkan kondisi ekonomi negara, daerah dan masyarakat. Pembangunan ekonomi dilakukan pada skala besar sampai dengan skala kecil. Pembangunan ekonomi bertujuan untuk meningkatkan ekonomi masyarakat yang kemudian juga berkaitan dengan peningkatkan kesejahteraan masyarakat.

Pembangunan ekonomi adalah sautu proses dimana pemerintah negara, daerah dan desa bersama masyarakat mengelola sumberdaya-sumberdaya yang ada dan membentuk suatu pola kemitraan antara pemerintah, sektor swasta dan masyarakat untuk meciptakan suatu lapangan kerja baru dan merangsang perkembangan kegiatan ekonomi.

Dengan kondisi Negara Indonesia yang terdiri atas pulau-pulau mengkibatkan pembangunan di Indonesia tidak maksimal jika hanya dilakukan oleh pemerintah pusat. Sehingga otonomi daerah menjadi langkah yang diambil dalam melakukan pemerataan pembangunan. Otonomi daerah adalah penyerahan wewenang pemerintah pusat kepada daerah otonom. Otonomi daerah diambil agar terciptanya pemerataan wilayah daerah, mendorong pemberdayaan masyarakat, keadilan sosial dan lain sebagainya.

Otonomi daerah memungkinkan setiap daerah membangun daerahnya berdasarkan kondisi sumber daya dan pola masyarakatnya. Selain otonomi daerah, pemerintah juga melaksanakan sistem otonomi desa. Otonomi Desa memberikan kewenangan yang luas kepada desa dalam pembangunan wilaya desa. Desa diberikan anggaran untuk menjalankan pemerintahan serta membangun masyarakat desa. Tujuan dari otonomi desa adalah untuk meningkatkan kesejahteraan masyarakat desa, mempercepat kemajuan kegiatan ekonomi pedesaan yang berkeadila dan mempercepat industrialisasi Desa, dapat meciptakan lapangan kerja dan banyak hal lainnya.

Secara teknis, pembangunan ekonomi dilakukan dengan berbagai sektor, dari pemberdayaan sumber daya alam, hingga dengan kebijakan-kebijakan ekonomi kreatif yang diambil oleh pemerintah dalam merangsang pembangunan dan pertumbuhan ekonomi daerah. Dalam skala kecil pembangunan ekonomi dilakukan oleh pemerintah desa. Pemerintah desa memiliki otoritas dalam mengambil kebijakan yang dibutuhkan dalam meningkatkan pembangunan ekonomi desa.

Kabupaten Siak merupakan salah satu daerah otonom di Indonesia Provinsi Riau. Kabupaten Siak terdiri dari 9 kelurahan dan 122 Desa. Semangat Kabupaten Siak dalam meningkatkan ekonomi masyarakat sesuai dengan UU No. 06 Tahun 2014 desa adalah melalui Badan Usaha Milik Desa (BUMDes). Di kabupaten Siak istilah Badan Usaha Milik Desa (BUMDes) disebut dengan Badan Usaha Milik Kampung. Hal tersebut menyesuaikan dengan perubahan penamaan Desa menjadi Kampung di Kabupaten Siak berdasarkan Peraturan Daerah Kabupaten Siak Nomor 1 Tahun 2015 Tentang perubahan penamaan Desa menjadi Kampung.

Sesuai dengan jumlah Kampung di Kabupaten Siak yaitu 122 Kampung, jumlah BUMKam juga berjumlah sama dengan jumlah Kampung yaitu 122 BUMKam. Badan Usaha Milik Kampung (BUMKam) merupakan instrumen pemberdayaan ekonomi lokal dengan berbagai ragam jenis usaha dengan potensi yang dimiliki desanya. Pengembangan potensi ini memiliki tujuan untuk meningkatkan kesejahteraan ekonomi warga desa melalui pengembangan usaha ekonomi.

BUMKam sejatinya sebagai lembaga sosial yang berpihak kepada kepentingan masyarakat melalui kontribusinya sebagai penyedia pelayanan ekonomi dan sosial. Disamping sebagai penyedia pelayanan ekonomi dan sosial BUMKam juga sebagai lembaga komersial dimana BUMKam bertujuan untuk mencari keuntungan melalui penjualan barang dan jasa yang diperuntukan kepada masyarakat. Berdasarkan Peraturan Bupati Siak Nomor 18 Tahun 2007 tentang Badan Usaha Milik Kampung, BUMKam memilik tujuan dan fungsi sebagai berikut. 
BUMKam dibentuk dengan tujuan :

a. Memperoleh keuntungan untuk memperkuat Pendapatan Asli Desa;

b. Memajukan perekonomian Desa;

c. Meningkatkan kesejahteraan masyarakat Desa;

d. Memberikan pelayanan terhadap kebutuhan masyarakat;

e. Meningkatkan pengelolaan aset - aset Desa yang ada.

BUMKam berfungsi sebagai motor penggerak perekonomian Desa dan kesejahteraan masyarakat Desa dengan cara :

a) Pembentukan usaha baru yang berakar dari sumber daya yang ada serta optimalisasi kegiatankegiatan ekonomi masyarakat Desa yang telah ada;

b) Pengumpulan modal usaha dari berbagai sumber;

c) Peningkatan kesempatan berusaha dalam rangka memperkuat otonomi Desa dan mengurangi pengangguran;

d) Membantu Pemerintah Desa dalam mengurangi dan meningkatkan kesejahteraan warga terutama masyarakat miskin di Desanya;

e) Memberikan pelayanan dan bantuan sosial kepada masyarakat Desa.

Dalam pengelolaan Badan Usaha Milik Kampung (BUMKam) terdapat macam-macam unit usaha. Unit usaha yang ada pada BUMKam Mineh Mandiri Kampung Minas Barat adalah sebagai berikut:

a. Unit Usaha Simpan-Pinjam;

b. BRI Link;

c. Toko Bangunan

Salah satu program dalam meningkatkan ekonomi masyarakat desa melalui BUMKam adalah Pelayanan jasa antara lain simpan pinjam, perkreditan, angkutan darat dan air, listrik Desa dan lain sejenisnya. Keberadaan program usaha ekonomi desa simpan pinjam sejatinya adalah untuk mendukung kegiatan ekonomi masyarakat melalui simpan pinjam.

Program UEK SP dianggap sebagai pendekatan terbaik dalam menanggulangi kemiskinan, yang bermuatan upaya pemberdayaan yang lebih luas dalam kehidupan sosial ekonomi masyarakat dengan fungsi membentuk kelembagaan masyarakat yang dikelola oleh masyarakat dan untuk masyarakat dengan menyediakan berbagai jasa keuangan untuk kegiatan ekonomi produktif bagi keluarga miskin. Melalui program Usaha Ekonomi Desa Simpan Pinjam ini masyarakat yang memiliki modal terbatas atau tidak memiliki modal untuk membangun usahanya dapat melakukan pinjaman sesuai aturan teknisnya. Berikut ini data tentang peminjam di BUMKam Mineh Mandiri.

Tabel 1.1

Data Peminjam Berdasarkan Jenis Kelamin

\begin{tabular}{cccr}
\hline No. & & Jenis Kelamin & Jumlah Peminjam \\
\hline 1. & Laki-Laki & & 133 Orang \\
\hline 2. & Perempuan & & 62 Orang \\
\hline & & Total & $\mathbf{1 9 5}$ \\
\hline
\end{tabular}

Sumber: BUMKam Mineh Mandiri, 2020.

Berdasarkan tabel diatas diketahui bahwa, pada tahun 2020 jumlah peminjam sebanyak 195 orang, yang terdiri dari laki-laki berjumlah 133 orang dan perempuan berjumlah 62 orang.

Table 1.2

Peminjam Berdasarkan Jenis Usaha

\begin{tabular}{llrr}
\hline No. & & Jenis Usaha & Orang \\
\hline 1. & Perdagangan & & 71 \\
\hline 2. & Pertanian & & 2 \\
\hline
\end{tabular}




\begin{tabular}{llr}
\hline 3. & Perkebunan & 115 \\
\hline 4. & Perikanan & 1 \\
\hline 5. & Jasa & 6 \\
\hline Jumlah & $\mathbf{1 9 5}$ \\
\hline
\end{tabular}

Sumber: BUMKam Mineh Mandiri, 2020

Berdasarkan Tabel diatas diketahui bahwa, pada tahun 2020 jumlah pinjaman sebanyak 195 orang yang terdiri dari beberapa usaha yaitu, sebanyak 71 orang berjenis usaha perdagangan, 2 orang pertanian, 115 orang perkebunan, 1 orang perikanan dan 6 orang di bidang jasa.

Pemberdayaan masyarakat adalah sebuah konsep pembangunan ekonomi yang merangkum nilainilai sosial. Konsep ini mencerminkan paradigma baru pembangunan, yakni yang bersifat "people centred, participatory, empowering, and sustainable" (Chambers, 1995). Sumadyo (2001) merumuskan tiga upaya pokok dalam setiap pemberdayaan masyarakat, yang disebutnya sebagai Tri Bina, yaitu: Bina Manusia, Bina Usaha, dan Bina Lingkungan.

Terhadap rumusan ini, Mardikanto (2003) menambahkan pentingnya Bina Kelembagaan, karena ketiga Bina yang dikemukakan (Bina Manusia, Bina Usaha, dan Bina Lingkungan) itu hanya akan terwujud seperti yang diharapkan, manakala didukung oleh efektivitas beragam kelembagaan yang diperlukan.

\section{METODE}

Jenis penelitian yang digunakan adalah penelitian deskriptif kualitatif. Alasan penulis menggunakan metode ini adalah bertujuan untuk mendapatkan pemahaman yang luas dan mendalam terhadap situasi dan kondisi serta hambatan yang terkait dengan "Pemberdayaan Masyarakat Melalui Unit Usaha Simpan Pinjam di Badan Usaha Milik Mampung Mineh Mandiri Kampung Minas Barat". Lokasi penelitian berada dibeberapa lokasi yaitu Pemerintah Kampung Minas Barat dan Badan Usaha Milik Kampung/ Unit Ekonomi Kampung Simpan Pinjam Kampung Minas Barat.

penelitian ini peneliti menggunakan teknik purposive sampling dimana peneliti memilih key informan dan informan yang peneliti anggap mengetahui tentang permasalahan penelitian. Sebagai key informan yang paling mengetahui bagaimana kondisi keseluruhan dari "Pengelolaan Simpan Pinjam UEK SP Kampung Minas Barat”. Pengumpulan data penelitian menggunakan tekhnik pengamatan/observasi, wawancara dan dokementasi. Analisis yang digunakan dalam Penelitian Kualitatif ini menggunakan pendekatan Analisis Kualitatif Deskriptif.

\section{HASIL DAN PEMBAHASAN}

\section{Pemberdayaan Masyarakat Melalui Unit Usaha Simpan Pinjam Di Badan Usaha Milik Kampung Mineh Mandiri Kampung Minas Barat.}

Tata kelola BUMKam berdasarkan Good Corporate Governance pengelolaan Badan Usaha Milik Kampung juga harus menerapkan Konsep Pemberdayaan Masyarakat, sehingga Badan Usaha Milik Kampung dapat maju dan berkembang bersamaan dengan meningkatnya kesejahteraan masyarakat dan pemberdayakan perekonomian masyarakat Kampung.

Pemberdayaan Masyarakat melalui Unit Usaha Simpan Pinjam pada Badan Usaha Milik Kampung Mineh Mandiri Kampung Minas barat berdasarkan konsep Pemberdayaan Masyarakat. 
Terdapat Empat indikator Pengelolaan BUMKam berdasarkan konsep pemberdayaan masyarakat yaitu Bina Manusia, Bina Usaha, Bina Lingkungan dan Bina Lembaga.

\section{Bina Manusia}

Bina Manusia, merupakan upaya yang pertama dan utama yang harus diperhatikan dalam setiap upaya pemberdayaan masyarakat. Hal ini, dilandasi oleh pemahaman bahwa tujuan pembangunan adalah untuk perbaikan mutu hidup atau kesejahteraan manusia. Di samping itu, dalam ilmu manajemen, manusia menempati unsur yang paling unik. Sebab, selain sebagai salah satu sumberdaya juga sekaligus sebagai pelaku atau pengelola manajemen itu sendiri.

Tujuan BUMKam didirakan atas keinginan masyarakat untuk berkembang. Salah satu perwujudan bina manusia dapat dilakukan melalui BUMKam. Dengan memanfaatkan potensi masyarakat dan potensi daerah tentu BUMKam dapat mewujudkan pemberdayaan masyarakat. Namun kenyataannya pada saat ini, bina manusia belum dapat diwujudkan oleh BUMKam Mineh Mandiri, salah satu unit usaha yaitu simpan pinjam yang seharusnya mampu memberikan stimulus kepada masyarakat ternyata belum kesampaian.

Unit usaha simpan pinjam pada BUMKam mineh mandiri pada saat ini berjalan layaknya koperasi dan Bank perkreditas rakyat. Kondisi ini sangat jelas terlihat sebab belum ada masyarakat yang berkembang dengan sentuhan BUMKam. Beberapa masyarakat yang mungkin kondisinya baik pasca peminjaman yaitu karena mereka sudah memiliki usaha yang sudah ditekuni, sehingga melakukan pinjaman sebagai penambahan modal bukan usaha yang dimulai dari Nol. Bahkan BUMKam sendiri belum memiliki program dalam melakukan bina manusia pada internal BUMKam Mineh Mandiri.

\section{Bina Usaha}

Bina Usaha menjadi suatu upaya penting dalam setiap pemberdayaan, sebab, Bina Manusia yang tanpa memberikan dampak atau manfaat bagi perbaikan kesejahteraan (ekonomi dan atau ekonomi) tidak akan laku, dan bahkan menambah kekecewaan. Sebaliknya, hanya Bina Manusia yang mampu (dalam waktu dekat/cepat) memberikan dampak atau manfaat bagi perbaikan kesejahteraan (ekonomi dan atau ekonomi) yang akan laku atau memperoleh dukungan dalam bentuk partisipasi masyarakat.

Begitu pun dengan pembinaan usaha Badan Usaha Milik Kampung. Badan Usaha Milik Kampung memiliki peran sebagai wadah untuk melakukan pemberdayaan ekonomi masyarakat kampung. Badan Usaha Milik Kampung memiliki unit-unit usaha untuk pemberdayaan masyarakan dan penyaluran usaha ekonomi kreatif kepada masyarakat. Tentang hal ini, Bina Usaha mencakup Pemilihan komoditas dan jenis usaha, Perencanaan Investasi dan Penetapan sumber-sumber pembiayaan, Pengembangan dan pengelolaan Sistem Informasi Bisnis, dan Pengembangan Sarana dan Prasarana Pendukung.

BUMKam Mineh Mandiri disebut dengan lembaga bisnis Kampung, BUMKam harus mampu menganalisa potensi yang ada di Kampung tersebut. BUMKam juga harus mampu membangun ekonomi masyarakat dengan menyesuaikan dengan kondisi masyarakat dan kondisi geografis Kampung. Akantetapi sampai pada hari ini BUMKam bergerak pasif menunggu program dan strategi dan Pemerintah Kampung dan Pengawas Kampung. BUMKam belum mampu berperan aktif untuk membentuk usaha-usaha kampung dan usaha masyarakat.

\section{Bina Lingkungan}

Selama ini, pengertian lingkungan, seringkali dimaknai sekadar lingkungan fisik, utamanya yang menyangkut pelestarian sumberdaya-alam dan lingkungan hidup. Tetapi, dalam praktek perlu disadari bahwa lingkungan sosial juga sangat berpengaruh terhadap keberlanjutan bisnis dan kehidupan. Terutama pada bisnis Badan Usaha Milik Kampung yang mengedepankan aspek kesejahteraan social. 
Lingkungan menjadi salah satu factor yang dapat dijadikan dasar dalam melakukan pemberdayaa masyarakat. Unit Usaha simpan pinjam dapat dijadika sumber anggaran bagi masyarakat untuk mengembangkan usaha sesuai dengan kebutuhan pribadi dan social. Misalnya di Kampung Minas Barat, terdapat beberapa danau yang bisa dijadikan untuk membuat budidaya keramba ikan. Masyarakat local dengan dorongan modal yang bersumber dari usaha simpan pinjam dan juga support dari BUMKam harusnya mampu memanfaatkan potensi tersebut dengan baik.

Namun BUMKam sebagai wadah belum mampu menjalankan perannya untuk meningkatkan antusiasme masyarakat dalam mengembangkan potensi daerah. Inilah yang menyebabkan tidak berjalannya bina lingkungan yang harusnya dilaksanakan oleh BUMKam Mineh Mandiri.

\section{Bina Lembaga}

Di depan telah dikemukakan, bahwa tersedianya dan efektivitas kelembagaan akan sangat berpengaruh terhadap keberhasilan Bina Manusia, Bina Usaha, dan Bina Lingkungan. Pengertian tentang kelembagaan, seringkali dimaknai dalam arti sempit sebagai beragam bentuk lembaga (kelompok, organisasi). Tetapi, kelembagaan sebenarnya memiliki arti yang lebih luas.

Kelembagaan akan mengikat sumber daya manusia didalamnya. Kelembagaan hadir dimasyarakat sebagai tatanan hidup pada bidang tertentu. Begitu pula dengan Badan Usaha Milik Kampung, sebagai lembaga social untuk memberdayakan masyarakat dan pengembangan ekonomi masyarakat. Badan Usaha Milik Kampung diorientasikan sebagai salah satu pilar yang berfungsi menyangga pelaku-pelaku ekonomi mikro yang berkembang di tingkat Desa.

Dasar pemikirannya kehadiran BUMKam adalah pertama, mampu menaungi aktivitas-aktivitas ekonomi yang dikelola secara kolektif oleh Desa, Kedua, strategi ini dipilih agar kelompok-kelompok penggiat ekonomi Mikro yang sedang ditumbuh kembangkan oleh pemerintah melalui Bantuan-bantuan langsung dapat terhubung dengan BUMKam. Dalam sebuah kelembagaan terdapat 4 komponen yaitu Komponen Person, Komponen Kepentingan, Komponen Aturan dan Komponen Struktur.

Persoalan yang ada saat ini adalah person yang ada di BUMKam Mineh Mandiri belum memenuhi kuantitas dan kualitas yang baik. Minimnya Person ini menyebabkan komponen kepentingan, komponen aturan serta komponen struktur tidak berjalan dengan baik. Diperlukan adanya penyegaran untuk mengisi kekurangan-kekurangan person pada BUMKam Mineh Mandiri. Disamping itu pelatihan-pelatihan harus lebih di giatkan setiap daerah dalam upaya meingkatkan sumberdaya manusia dan menyelenggarakan pemberdayaan masyarakat.

\section{KESIMPULAN}

Hasil Penelitian ini menyimpulkan bahwa pemberdayaan masyarakat melalui unit usaha simpan pinjam pada Badan Usaha Milik Kampung Mineh Mandiri Kampung Minas barat belum baik. Hal tersebut disebabkan oleh bina manusia unit usaha simpan pinjam pada BUMKam Mineh Mandiri belum dilakukan sehingga sumber daya manusia yang ada belum mampu menghadirkan strategi yang tepat dan program yang unggulan terkait pemberdayaan masyarakat. Pada bina usaha, unit usaha BUMKam Mineh Mandiri masih belum aktif mendorong masyarakat untuk memberdayakan ekonominya melalui BUMKam Mineh Mandiri.

Hal tersebut karena kurang aktifnya peran BUMKam kepada masyarakat sehingga masyarakat kurang antusias terhadap BUMKam Mineh Mandiri. Selanjutnya Bina lingkungan, BUMKam Mineh Mandiri belum pernah melakukan bina lingkungan yaitu memastikan bahwa lingkungannya mendapatkan manfaat dari adanya BUMKam tersebut. Terakhir Bina Lembaga, ada banyak kelemahan kelembagaan di BUMKam Mineh Mandiri ini, baik secara person BUMKam, kemudian BUMKam pun tidak memiliki 
strategi dan program yang berasal dari ide setiap person BUMKam, profil yang belum tersedia, hingga aturan-aturan AD/ART yang tidak kuat. Dengan demikian secara keseluruhan pengelolaan unit usaha simpan pinjam pada badan usaha milik kampung mineh mandiri kampung minas barat belum dikelola dengan optimal.

Hasil penelitian ini menyimpulkan bahwa, faktor penghambat dalam pemberdayaan masyarakat melalui unit usaha simpan pinjam di Badan Usaha Milik Kampung Mineh Mandiri Kampung Minas adalah sebagai berikut. keterbatasan Sumber daya manusia di internal BUMKam sehingga belum mampu berperan aktif dalam mensosialisasikan BUMKam ditengah masyarakat serta masih belum mampu menghadirkan strategi dan program yang mampu tepat, guna mengembangkan BUMKam. Keterbatasan sumber daya pada internal BUMKam Mineh Mandiri ini menyebabkan tidak terlaksananya pemberdayaan masyarakat dan peningkatan ekonomi kampung.

Faktor penghambat selanjutnya adalah kurangnya kesadaran masyarakat dan kurangnya antusias masyarakat terhadap BUMKam Mineh Mandiri Hal tersebut terlihat pada saat ini BUMKam mengadakan rekrutmen namun masyarakat yang ingin bergabung hanya beberapa orang saja. Minimnya Kesadaran masyarakat juga terlihat dari para peminjam yang tidak ingin melunasi pinjaman karena menganggap dana BUMKam tersebut bersumber dari dana hibah yang memang harus diserahkan atau digunakan untuk kepentingan masyarakat.

\section{SARAN}

Berdasarkan hasil penelitian yang telah dilakukan penulis mengenai pengelolaan unit usaha simpan pinjam pada badan usaha milik kampung mineh mandiri kampung minas barat, penulis memberi saran sebagai berikut:

1. Unit Usaha Simpan Pinjam Di BUMKam Mineh Mandiri harus mampu menghadirkan strategi dan program yang sesuai dengan keadaan masyarakat serta sesuai dengan potensi Kampung Minas Barat. System tata kelola BUMKam harus mampu menghadirkan inovasi sehingga dapat mengembangkan BUMKam Mineh Mandiri.

2. BUMKam Mineh Mandiri, Pemerintah Kampung, dan Lembaga Pengawasan Kampung harus ikut serta dalam rekrtumen. Sehingga dapat melakukan seleksi yang baik untuk menghadirkan sumber daya manusia yang potensial untuk melaksanakan pemberdayaan masyarakat dan mengembangkan BUMKam Mineh Mandiri.

3. Pemerintah harus mengatur mengenai legalitas BUMKam di mata hukum, dan mengatur standar kualifikasi untuk merekrut dan menjaring sumber daya manusia di Badan Usaha Milik Desa/Kampung.

\section{DAFTAR PUSTAKA}

[1] Almasdi, Syahza dan Suarman. 2013. Strategi Pengembangan Daerah Tertinggal dalam Upaya Percepatan Pembangunan Ekonomi Pedesaan. Jurnal Ekonomi Pembangunan. 14 (1): 126-139.

[2] Arikunto, Suharsimi. 1993. Manajemen Penelitian. Jakarta: Rineka Cipta.

[3] Byars, L I. Dan Leslie W. Rue. 2006. Human Resource Management. 8th Edition. McGraw-Hill. 
[4] Chambers. R. 1995. Lembaga Penelitian, Pendidikan, Penerapan Ekonomi dan Sosial, Pembangunan Desa Mulai dari Belakang. Jakarta.

[5] Hasibuan, Malayu Sp. 2012. Manajemen SDM. Edisi Revisi, Cetakan Ke Tigabelas. Jakarta : Bumi Aksara.

[6] Mardikanto, Totok, and, Soebianto, Poerwoko. 2003.Pemberdayaan Masyarakat Dalam Perspektif kebijakan Publik. Alfabeta. Surakarta.

[7] Peraturan Daerah Kabupaten Siak Nomor 18 Tahun 2007 tentang Badan Usaha Milik Desa

[8] Rusnani, dkk. 2016. Pengembangan Aplikasi Angsuran Pembayaran Usaha Ekonomi Desa Simpan Pinjam (UED-SP) Bantan Tengah. Jurnal Inovtek Polbeng. 1(1): 49-56.

[9] Sumadyo, Hadi, 2001. Psikologi Sosial. Bandung : Pustaka Setia

[10] Singarimbun, Masri dan Sofian Effendi. 2006. Metode Penelitian Survei (Editor). Jakarta: LP3ES.

[11] Sugiyono. 2009. Metode Penelitian Kuantitatif, Kualitatif dan R\&D. Bandung: Alfabeta.

[12] Suharto, Edi. 2006. Membangun Memberdayakan Rakyat. PT. Refika Aditama.

[13] Zaili Rusli, dkk. 2012. Pemberdayaan Masyarakat Miskin Melalui Program Unit Ekonomi DesaSimpan Pinjam (UED-SP).3(2) : 67-72. 